\title{
Parallel PCS Interconnection Current Surge Elimination Technique Using a Coupled Inductor
}

\author{
Jung-Muk Choe ${ }^{*}$, Byeng-Joo Byen*, and Gyu-Ha Choe ${ }^{\dagger}$ \\ ${ }^{* \dagger}$ Department of Electrical Engineering, Konkuk University, Seoul, Korea
}

\begin{abstract}
This study proposes a coupled inductor method for the parallel operation of a power conditioning system (PCS). When primary and secondary currents flow in the same direction in a coupled inductor, total flux and inductance are cancelled; when currents flow in opposite directions, each flux becomes an individual inductor. These characteristics are applied in the parallel operation of a PCS. To connect at a grid code, abnormal current, which is barred under the grid connection code, is blocked by using a coupled inductor. A design based on the capacity and current duration time of a PCS is verified through hardware implementation. Experiment results show the effectiveness of variance reduction.
\end{abstract}

Key words: Battery, Coupled inductor, Photovoltaic, Power conditioning system, Reconnection

\section{INTRODUCTION}

Power conditioning systems (PCSs) have been widely implemented in new and renewable energy systems in recent years. In particular, they are used in new renewable energy sources, such as solar cells, fuel cell generation, and batteries, all of which must convert DC source power into AC output.

The inverter input voltage in a PCS is always higher than the peak grid voltage. However, most current and prospectively utilized energy sources provide a low-voltage DC output. A one-stage PCS consists of an inverter and a transformer. This system can achieve galvanic isolation and solve output voltage difference by implementing a specific turn ratio. Although using a transformer has several advantages, transformerless systems have recently gained preference in residential solar PCS applications. Nevertheless, specific issues with respect to high efficiency and low cost must be addressed. Without a transformer, a two-stage PCS can convert an energy source to a higher voltage $\mathrm{DC}$ before changing it into $\mathrm{AC}$ for grid tie applications (Fig. 1) [1], [2]. The first stage of this process is the boost stage, which requires using a step-up DC-DC converter with a low-voltage DC input. The second stage involves using a DC-AC inverter to implement grid connection. The two-stage PCS exhibits high efficiency and consumes a

Manuscript received Apr. 17, 2014; accepted Jul. 17, 2014 Recommended for publication by Associate Editor Tae-Won Chun. ${ }^{\dagger}$ Corresponding Author: ghchoe@konkuk.ac.kr

Tel: +82-2-450-3486, Fax: +82-2-450-1452, Konkuk University

*Department of Electrical Engineering, Konkuk University, Korea relatively small amount of space, which makes it commercially preferable [3], [4].

To add capacity to a PCS, additional power electronic systems, which require additional $\mathrm{AC}$ power, can be built into the PCS within a parallel structure; most of such systems have separate DC and connected AC sides [5]-[8]. A multi-unit system is operated synchronously in parallel, with each unit having its own controller. Therefore, the components of a parallel PCS do not always operate at exactly the same time. Connecting inverters in parallel can cause a zero-sequence circulating current, which can damage system or power sources [7]-[10]. To avoid this phenomenon, some applications use a transformer to implement an isolation approach [11], [12]. Chen et al. [14] proposed using a triport transformer in stand-alone PCSs, such as uninterruptible power systems, to prevent circulating currents through phase-difference compensation. When connecting commercial products to the grid, a multi-winding transformer is used to prevent circulating currents [15]. However, transformer-type systems have several disadvantages, as discussed earlier. Moreover, parallel systems are expensive and bulky. Given that converters are added in parallel to a system, such approaches become practically unaffordable. Therefore, adopting transformerless systems whenever possible in multi-unit applications is advantageous. For example, interphase inductors are used in parallel off-grid inverters [10] and additional coupled inductors are used in off-grid inverters [16] and motor drives [7]. A coupled inductor differs from transformers and interphase inductors, that is, 


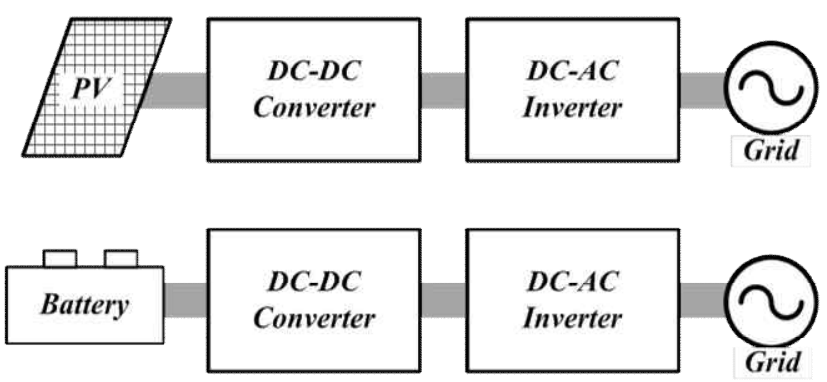

Fig. 1. Two-stage tranformerless PCS diagram.

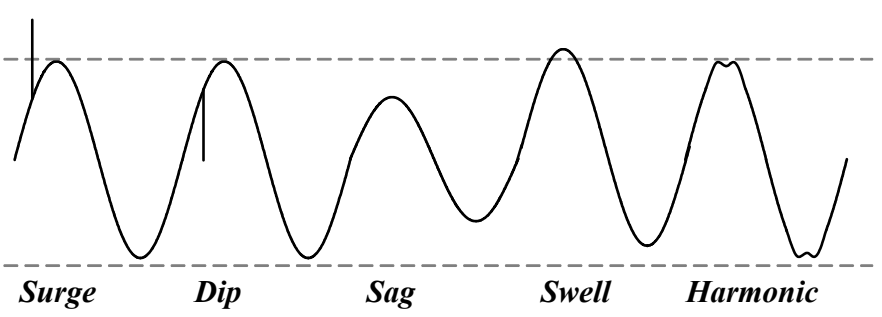

Fig. 2. Utility waveform distortions.

under ideal circumstances, the voltage drop of a coupled inductor is zero when the sum of the magneto motive force drops around the loop [17]. Although Liu et al. [15] proposed a voltage control method for parallel circulation current suppression, their method is unsuitable for use in all situations.

A grid-connected PCS controller receives phase data from the mother grid and generates an output phase. However, a tiny controller time gap exists in this process, which causes circulating currents and instantaneous surges and dips in the initial current. Fig. 2 illustrates several utility waveform distortions that can affect power quality. Some distortions originate in power electronics, whereas some surges and dips arise from initial interconnection characteristics and high speed "dv/dt" and "di/dt" events [18], [19]. Several regulatory standards specify the interconnection requirements of distributed generation units in power systems, including IEEE Standards 1547-2003, 1547.2-2008, and 1547.1-2005 and IEC 61727. Furthermore, electromagnetic compatibility is regulated under interconnection electric load regulation standards IEC 2009, 950, and 61000-3-2, 2005.

This study aims to propose a coupled inductor-based interconnection surge elimination method that can be adopted in a grid-connected PCS. The proposed method has several advantages. First, circulation current is suppressed. Second, PCS reconnection condition, which is governed under the newly enacted international grid code, is smoothly obtained. The analysis and experiment results obtained from two $3 \mathrm{~kW}$ PCSs are presented in this study to validate the proposed coupled inductor method.

\section{PARALLEL PCS OPERATION AND DESIGN}

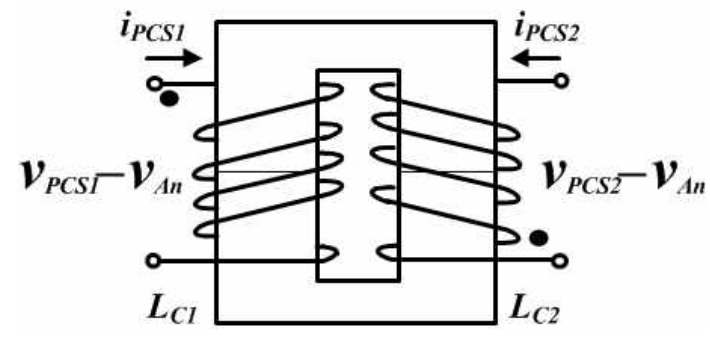

(a) $\mathrm{C}$ core structure.

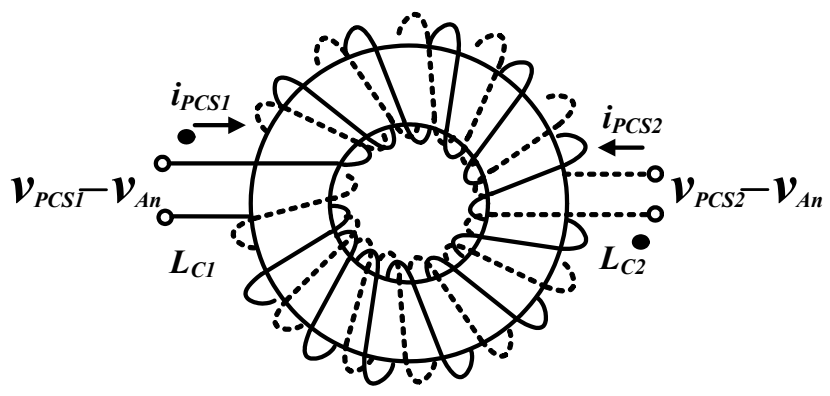

(b) Toroidal core structure.

Fig. 3. Structure of the coupled inductor.

\section{A. Structure of the Coupled Inductor}

The coupled inductor has two windings: the primary and secondary windings, which are shown in Fig. 3. When primary and secondary currents flow in the same direction, total flux in the core has the opposite polarity, which causes its cancellation. Total flux indicates the sum of each self-inductance and mutual inductance.

When currents flow in opposite directions, however, each generated flux functions as an individual inductor. When combined, these fluxes generate a total flux that is greater than either individual flux. The impedance of the coupled inductor is reduced when the output vectors of the parallel inverters are perfectly synchronized. However, a transient difference in the outputs leads to a high inductance that blocks the instantaneous inrush current.

\section{B. Coupled Inductor in Parallel PCS}

Fig. 4 shows two PCSs connected with a coupled inductor. Each PCS is equivalent to an ideal voltage source, namely, Vpcs1 and Vpcs2, with equivalent output impedances Lpcs1 and Lpcs2, respectively. A load is connected between the coupled PCSs and the grid, with the PCSs controlling the connection of a renewable source to the grid. As shown in Fig. 4, all the currents are theoretically supplied by the two PCSs.

According to magnetic coupled circuit theory, the inductance voltage is given by

$$
\begin{aligned}
& v_{p c s 1}-v_{A n}=L_{C 1} \frac{d i_{p c s 1}}{d t}-M \frac{d i_{p c s 2}}{d t}, \\
& v_{p c s 2}-v_{A n}=L_{C 2} \frac{d i_{p c s 2}}{d t}-M \frac{d i_{p c s 1}}{d t} .
\end{aligned}
$$




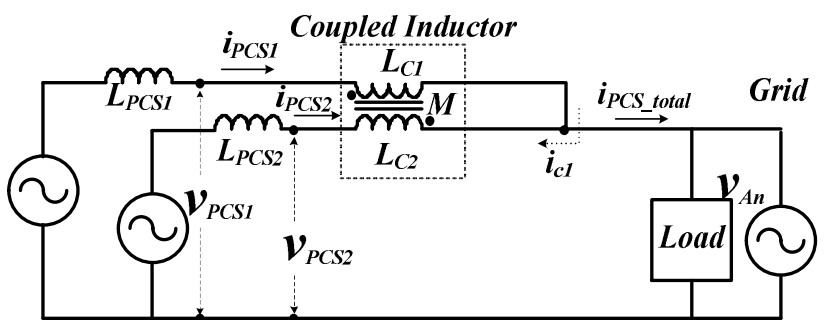

Fig. 4. Equivalent circuit of the coupled inductor in parallel PCS.

In an ideal case, the PCS output voltage and load voltage are equal, that is, the two PCSs generate the same current. Accordingly, the mutual inductance is the same as the self-inductance. Consequently, the voltage drop is zero because of the additional coupled inductor.

\section{Analysis of the Circulation Current}

During daytime, photovoltaic (PV) sources feed power into the AC grid through the PCS. The voltages of the parallel PCS system shown in Fig. 4 can be expressed as follows:

$$
\begin{aligned}
& \dot{V}_{p c s 1}=\dot{V}_{A n}+L_{p c s 1} \dot{i}_{p c s 1}, \\
& \dot{V}_{p c s 2}=\dot{V}_{A n}+L_{p c s 2} \dot{i}_{p c s 2} .
\end{aligned}
$$

In the parallel system, the current from one PCS can flow to the other instead of to the grid when a PCS output voltage vector difference occurs. The vector of the circulation current is defined as follows [15], [22]:

$$
\dot{i}_{c 1}=\frac{\left(\dot{i}_{p c s 1}-\dot{i}_{p c s 2}\right)}{n} .
$$

In Equation (5), $n$ is the number of parallel PCS. The difference between the two PCSs is equivalent to the voltage vector as follows:

$$
\Delta \dot{V}_{p c s}=\dot{V}_{p c s 1}-\dot{V}_{p c s 2}
$$

The circulation current in the system can be given as follows [15]:

$$
\dot{i}_{c i}=\frac{\Delta \dot{V}_{p c s}-\left(\frac{L_{p c s 1}-L_{p c s 2}}{2}\right) \cdot \dot{i}_{P C S_{-} t o t a l}}{L_{p c s 1}+L_{p c s 2}} .
$$

By setting the output impedances of the two PCSs to the same value, Equation (7) can be simplified into

$$
i_{c i}=\frac{\Delta \dot{V}_{p c s}}{2 L_{p c s}} .
$$

Considering that the circulation current is determined by the voltage vector and the output impedances, additional inductance can reduce the circulation current even if a voltage vector difference occurs.

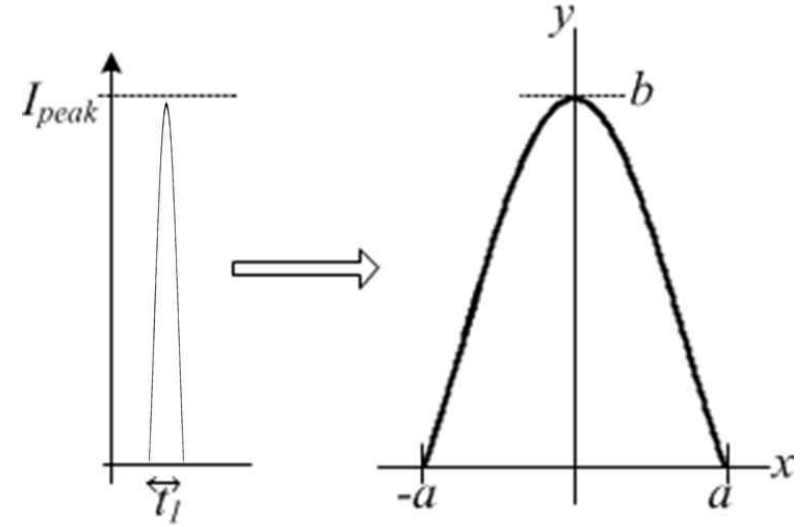

Fig. 5. Waveform of the surge current.

\section{Design of the Coupled Inductor}

The inductance of the coupled inductor must be designed to decrease the instantaneous surge in the circulation current. Such design concept should consider the worst-case condition that occurs at peak current and a phase difference of $180^{\circ}$ when the PCS is reconnected after failure. In this case, the current becomes an impulse that is several microseconds long. Fig. 5 shows the waveform of the surge current (the right side of the figure expands the time axis of the left side). The area of current waveform $A$ ' can be expressed as follows:

$$
A=2 \int_{0}^{a}\left(-\frac{b}{a^{2}} x^{2}+b\right) d x
$$

where $x$ is given by

$$
d x=a \sin \theta d \theta .
$$

By using Equation (10), Equation (9) can be rewritten as follows:

$$
\begin{aligned}
A & =2 \int_{0}^{\frac{\pi}{2}}\left(-b \sin ^{2} \theta+b\right) \cdot a \cos \theta d \theta \\
& =2 a b\left[\sin \theta-\frac{1}{3} \sin ^{3} \theta\right]_{0}^{\frac{\pi}{2}}=\frac{4}{3} a b .
\end{aligned}
$$

By substituting the short surge current duration $t_{l}=2 a$ and $I_{\text {peak }}=b$ into Equation (11), the area of the surge current waveform is obtained as follows:

$$
A=\frac{4}{3} \cdot\left(I_{\text {peak }}\right) \cdot\left(\frac{1}{2} \cdot t_{1}\right)=\frac{2}{3} \cdot I_{\text {peak }} \cdot t_{1}=K \cdot I_{\text {peak }} \cdot t_{1},
$$

where $k$ is the ratio of the square impulse to the surge current, which is defined differently in the current study from that in a previous work [23]. By using the ratio

$$
K=\frac{2}{3}
$$

derived from Equation (12), we can obtain highly accurate results.

The presence of the additional inductor increases the 
duration of the surge pulse. The relationship between the original duration $t_{1}$ and the increased duration $t_{2}$ can be expressed as follows:

$$
K \cdot I_{\text {peak }} \cdot t_{1}=\int_{0}^{t_{2}} i_{L} d t
$$

As mentioned earlier, voltage phase difference affects the current, which is obtained as follows:

$$
\begin{aligned}
i_{L_{C 1}} & =\frac{1}{L_{C 1}} \int_{0}^{t_{2}} v_{L_{C 1}} d t \\
& =\frac{1}{L_{C 1}} \int_{0}^{t_{2}} V_{P C S 1} \cos \omega t-V_{P C S 2} \cos (\omega t-\theta) d t .
\end{aligned}
$$

Each inductance of the coupled inductor pair can then be obtained as follows:

$$
\begin{aligned}
L_{C 1}= & \frac{V_{R M S}}{K \cdot I_{P C S_{-} \text {peak }} t_{1} \omega^{2}} . \\
& \left\{1-\cos \omega t_{2}-\cos \theta+t_{2} \sin \theta+\cos \left(\theta+\omega t_{2}\right)\right\} .
\end{aligned}
$$

PCS peak current is determined by the capacity of the system, for example, the peak current for a $3 \mathrm{~kW}$ system is approximately $18 \mathrm{~A}$ at a grid condition of $220 \mathrm{~V}_{\mathrm{RMS}}$. In this case, surge current duration $\left(t_{l}\right)$ is $0.05 \mathrm{~ms}$. To decrease current, this duration can be extended to $5 \mathrm{~ms}$ (that is, to $t_{2}$ ). Accordingly, inductance $L_{C l}$ can be obtained as follows:

$$
\begin{aligned}
L_{C 1} \geq & \frac{220 \mathrm{~V}}{2 / 3 \cdot 18 \mathrm{~A} \cdot 0.05 \cdot 10^{-3} \mathrm{sec} \cdot 377^{2}} \\
& \cdot\left\{1-\cos 2 \pi \cdot 60 \mathrm{~Hz} \cdot 5 \cdot 10^{-3} \mathrm{sec}\right. \\
& -\cos \pi / 2+5 \cdot 10^{-3} \mathrm{sec} \cdot \sin \pi / 2 \\
& \left.+\cos \left(\pi / 2+2 \pi \cdot 60 \mathrm{~Hz} \cdot 5 \cdot 10^{-3} \mathrm{sec}\right)\right\} \\
& =1.24 \times 10^{-3} \text { Henry }
\end{aligned}
$$

$L_{C l}$ is the inductance of only one of the coupled inductor pair. A double inductance is considered when designing a coupled inductor.

\section{E. Coupled Inductor Geometry and Material Design}

Soft magnetic material cores, which allow great PCS compactness and low weight, are widely used in power conversion applications. The core loss factor is an important factor in an energy transfer system. Although metal powder materials have the most favorable core loss factors [20], cost should be considered for the purpose of mass production. To decrease cost, improved Si steel "JNHF-Core" is chosen for the inductor core material used in this study. Unlike conventional $\mathrm{Si}$ steel, which contains $3.5 \%$ or less $\mathrm{Si}$, the chosen material has a $\mathrm{Si}$ content of $6.5 \%$, which minimizes core loss and maximizes permeability. Table I lists the inductor design parameters of the fabricated PCSs. The volume of an inductor is related to the area product $A_{p}$, which is the product of the window area $W_{a}$ and the core cross
TABLE I

DESIGN PARAMETERS OF THE COUPLED INDUCTOR

\begin{tabular}{lcc}
\hline \multicolumn{3}{c}{ Design parameters of the coupled inductor } \\
\hline Inductor voltage & Symbol & Value \\
Magnetic material permeability & $V_{L C 1+L C 2}$ & $15 \mathrm{~V}$ \\
Flux density & $\mu_{m}$ & 4100 \\
Window utilization & $B_{m}$ & $1.15 \mathrm{~T}$ \\
Waveform factor & $K_{u}$ & 13 \\
Temperature & $K_{f}$ & 4.44 \\
increase goal & $T_{r}$ & $50{ }^{\circ} \mathrm{C}$ \\
Apparent power & $P_{t}$ & $60 \mathrm{~W}$ \\
Transformer current density & $J$ & 5.03 \\
Frequency & $f$ & $60 \mathrm{~Hz}^{2}$ \\
Window area $\left(F^{*} G\right)$ & $W_{a}$ & $5 \mathrm{~cm}^{2}$ \\
Core cross section $\left(D^{*} E\right)$ & $A_{a}$ & $12 \mathrm{~cm}^{2}$ \\
\hline
\end{tabular}
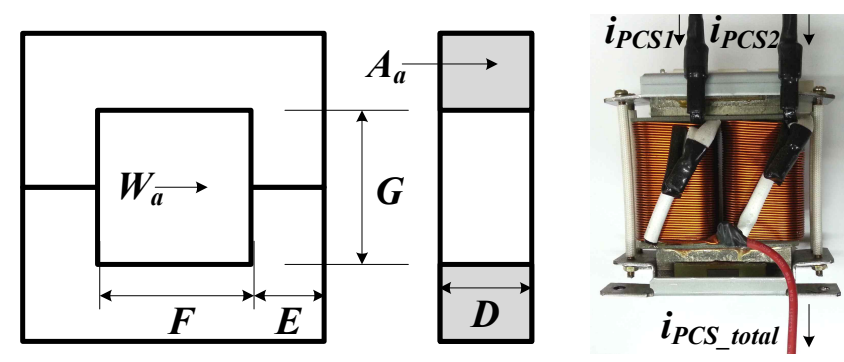

Fig. 6. Left: Core outline that shows the window area $(W a=F$. $G)$ and core cross section $(A c=D \cdot E)$; right: photo of the coupled inductor.

section $A_{c}$, as shown in Fig. 6. The area product can be obtained from the inductance, material factors, and apparent power as follows [21]:

$$
A_{p}=\frac{P_{t}}{K_{f} K_{u} B_{m} J f} \quad \mathrm{~cm}^{4} .
$$

Apparent power should have sufficient margins if an airgap does not exist in the inductor. The number of inductor turns is obtained from the following equation [21]:

$$
N_{L}=\frac{V_{L}\left(10^{4}\right)}{K_{f} \cdot B_{m} \cdot f \cdot A_{c}} .
$$

Given an inductor core volume of $60 \mathrm{~cm}^{3}$ and a total turn ratio of 96 turns, the magnetic inductance of the inductor is calculated to be $3.8 \mathrm{mH}$ for a single inductor $\left(L_{C l}\right)$ and 1.48 $\mathrm{mH}$ for the coupled inductor $\left(L_{C 2}\right)$.

\section{EXPERIMENT AND RESULTS}

Fig. 7 shows a circuit that consists of parallelPCSs with 


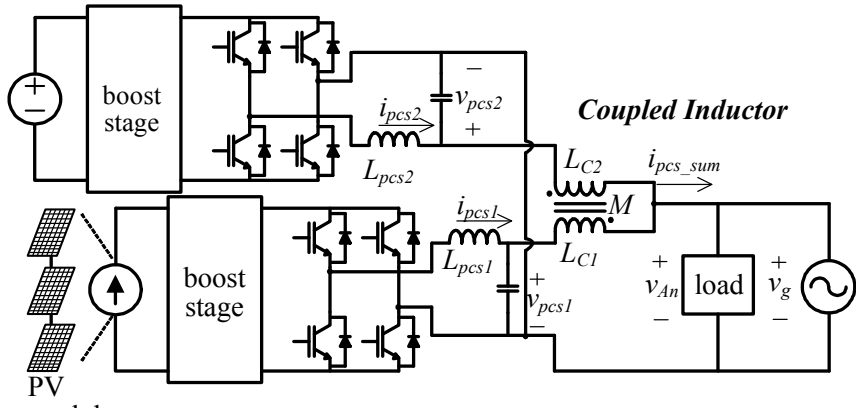

modules

Fig. 7. Experimental circuit of grid-connected PCSs.

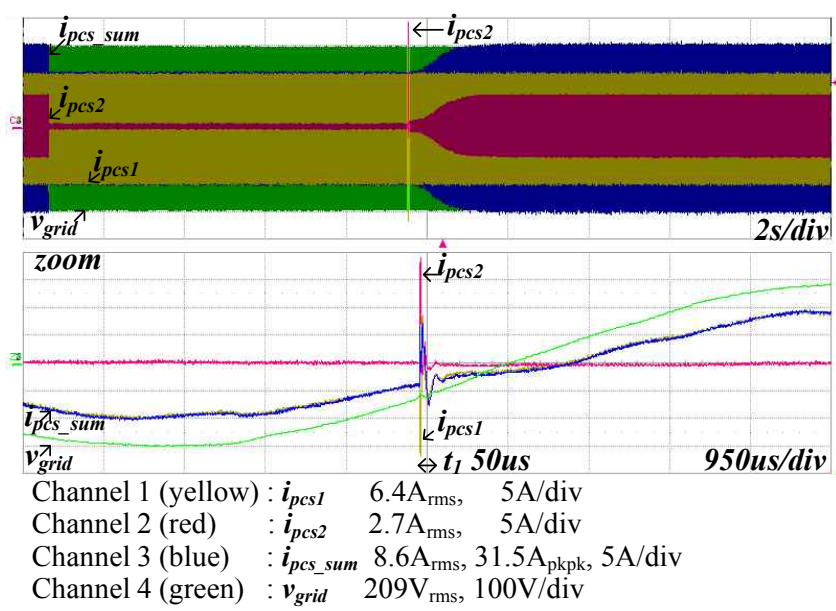

(a) Direct connection.

Fig. 9. Waveforms of $i_{P C S 1}, i_{P C S 2}, v_{\text {grid }}$, and $i_{P C S}$ total in parallel PCSs.

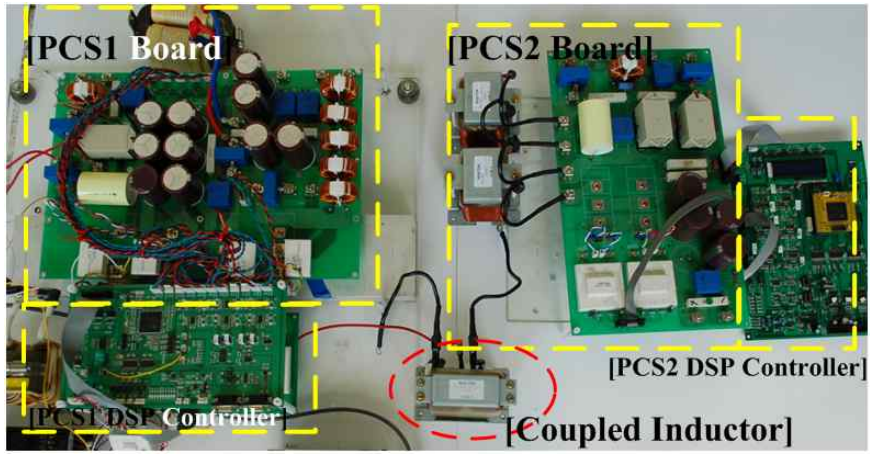

Fig. 8. Grid-connected $3 \mathrm{~kW}$ PCS prototype.

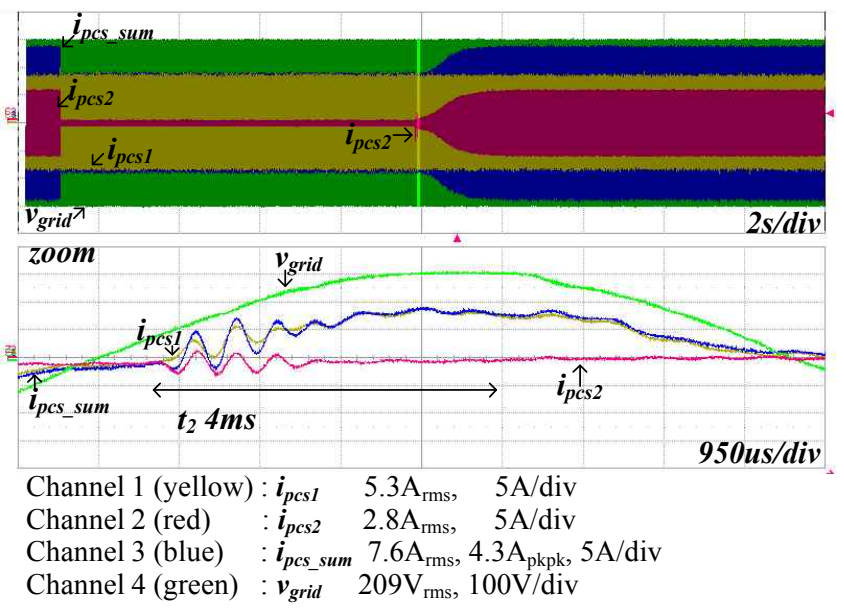

(b) Coupled inductor connection.

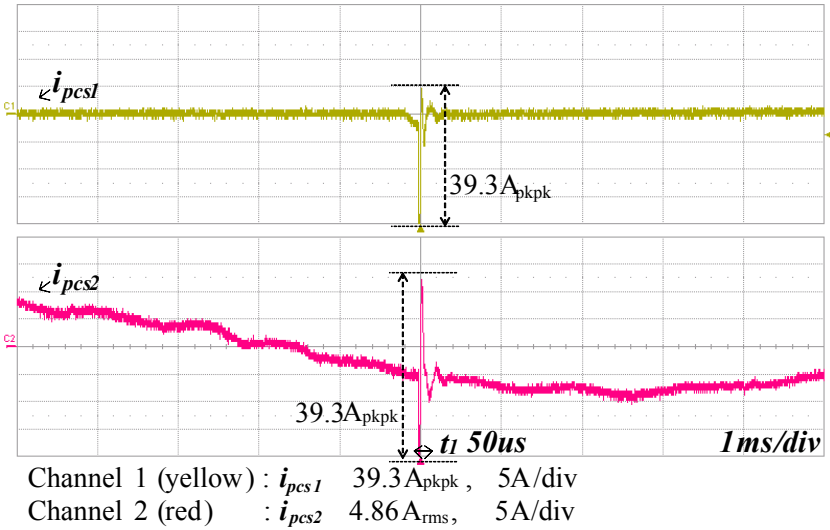

(a) Direct connection.

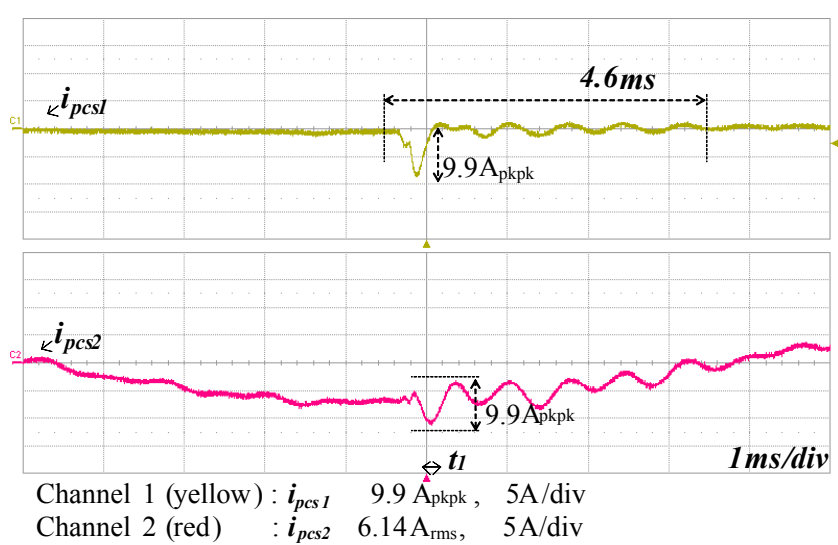

(b) Coupled inductor connection.

Fig. 10. Output current waveforms of $i_{P C S 1}$ and $i_{P C S 2}$ in parallel PCSs with opposite reconnection.

the proposed coupled inductor. For the experiment, a single-phase grid-connected PCS is fabricated with PV modules and a DC source used as input sources. The capacity is $3 \mathrm{~kW}$, which is popular in residential models.

Given that the series voltage of a typical solar module is lower than the minimum DC-link voltage, a two-stage PCS topology is selected for the test. Fig. 8 shows a photograph of the two $3 \mathrm{~kW}$ PCS prototypes, in which the first stage boosts the voltage and the second stage inverts $\mathrm{AC}$ to connect with a
$220 \mathrm{~V}_{\mathrm{RMS}}$ single phase. These prototypes have the same topologies. Both control boards consist of a gate driver, a signal conditioning circuit, and a 32 bit digital signal processor with interface circuitries. To measure input and output voltages as well as input current, a closed-loop-type Hall effect LV-20P voltage sensor and LA-50P current sensor (LEM, Beijing, China) are employed. In the power circuit, all switching devices are insulated-gate bipolar transistor SKM100GB128D. The inductance of the output filter is 4 
$\mathrm{mH}$. In a grid-tied situation, the quality of a distributed source is important, and instantaneous surge must be compensated for by, for example, a coupled inductor, such as the one assessed in this experiment. The out-of-phase situation at the point of common coupling (PCC) is PCS reconnection after failure. Figs. 9 and 10 compare the output current performances under reconnection at $5 \mathrm{~A} / \mathrm{div}$ and a voltage slew-rate of $100 \mathrm{~V} / \mathrm{div}$, respectively. The waveform in Fig. 9 shows the reconnection of PCS2 while operating PCS1. The PCS2 current turns off and then reconnects over a total of $9 \mathrm{~s}$. In Fig. 9(a), the surge current attains a peak of $31.5 \mathrm{~A}$, during which the reconnected current is not zero. Hence, power increases instantaneously to a high level, and PCC voltage is altered. After the coupled inductor is installed, the circulating current is significantly reduced, as shown in Fig. 9(b). The surge currents are reduced by $4.3 \mathrm{~A}$ and lasted for only $4 \mathrm{~ms}$. Fig. 10 compares the experimental results with opposite reconnection. When PCS1 is reconnected, the surge current reaches 39.3 A, as shown in Fig. 10(a). Fig. 10(b) shows the experimental results obtained when the coupled inductor is installed. In this case, surge currents are reduced by 9.9 A. Operation during reconnection is similar to that prior to coupled inductor installation.

\section{CONCLUSIONS}

A coupled inductor connection for parallel PCS operation is proposed to achieve high output performance. The significant results of our assessment are summarized as follows.

1) Parallel PCS operation differs from the operation of a single system. Given that the total system is influenced by the abnormal operation of a single PCS, the output phase will not be synchronized with the grid and the resulting circulation current can damage the PCS.

2) The design guide for our coupled inductor is based on PCS capacity and circulation current duration time.

3) The sum of the output surge is reduced by $87 \%$ by introducing the coupled inductor. Reduction in surge during reconnection is demonstrated.

In our experimental assessment, parallel single-phase $3 \mathrm{~kW}$ PCSs are fabricated and tested in various situations to demonstrate the performance of the proposed method. The results indicate that the coupled inductor produces a circulation current compensation of $87 \%$, which suggests that its use in improving performance is justified. However, one drawback in implementing the proposed system arises from the fact that adding an additional inductor tends to increase the size and cost of a system. To mitigate these factors, further efforts can be directed toward improving the compensation control method during vector difference duration. Reflection in the output impedance variation in the inverter current controller gain improves current quality during that time.

\section{ACKNOWLEDGMENT}

This paper was supported by Konkuk University in 2013.

\section{REFERENCES}

[1] R. Teodorescu, P. Rodriguez, and M. Liserre, "Power electronics for PV power systems integration," in Proc. Int. Conf. Ind. IEEE ISIE Symp, pp. 4532-4614, Jul. 2010.

[2] T. Kerekes, M. Liserre, R. Teodorescu, C. Klumpner, and M. Summer, "Evaluation of three-phase transformerless photovoltaic inverter topologies," IEEE Trans. Power Electron., Vol. 24, No. 9, pp. 2202-2211, Sep. 2009.

[3] J. S. Lai, "Power conditioning circuit topologies," IEEE Ind. Electron. Mag., Vol. 3, No. 2, pp. 24-34, Jun. 2009.

[4] R. Gonzalez, J. Lopez, P. Sanchis, and L. Marroyo, "Transformerless inverter for single-phase photovoltaic systems," IEEE Trans. Power Electron., Vol. 22, No. 2, pp. 693-697, Mar. 2007.

[5] C. Keller and Y. Tadros, "Are paralleled IGBT modules or paralleled IGBT inverters the better choice," 5th European Conf. Power Electronics and Applications, pp.1-6, 1993.

[6] N. Seki and H. Uchino, "Which is better at a high power reactive power compensation system, high PWM frequency or multiple connection," in Proc. IAS, pp. 946-953, 1994.

[7] S. Ogasawara , J. Takagaki and H. Akagi, "A novel control scheme of a parallel current-controlled PWM inverter," IEEE Trans. Ind. Appl., Vol. 28, No. 5, pp. 1023-1030, Sep./Oct. 1992.

[8] T. Kawabata and S. Higashino, "Parallel operation of voltage source inverters," IEEE Trans. Ind. Appl., Vol. 24, No. 2, pp. 281-287, Mar./Apr. 1988.

[9] Y. Komatsuzaki, "Cross current control for parallel operating three-phase inverter," in Proc. PESC, pp. 943 $-950,1994$.

[10] S. Fukuda and K. Matsushita, "A control method for parallel-connected multiple inverter systems," in Proc. Power Electronics and Variable Speed Drive Conference, pp.175-180, 1998.

[11] J. Holtz, W. Lotzkat, and K. Werner, "A high-power multitransistor-inverter uninterruptable power system," IEEE Trans. Power Electron., Vol. 3, No. 3, pp.278-285, Jul. 1988.

[12] J. W. Dixon and B. T. Ooi, "Series and parallel operation of hysteresis current-controlled PWM rectifiers," IEEE Trans. Ind. Appl., Vol. 25, No. 4, pp.644 -651, Jul./Aug. 1989.

[13] K. Harada, A. Katsuki, K. Murata, T. Nakamizo, F. Tominaga, and Y. Kawata, "On the parallel operations of triport UPS systems," in Proc. 7th Int. Conf. INTELC, pp. 111-116, 1985.

[14] Y. M. Chen, Y. C. Liu, and F. Y. Wu, "Multi-input DC/DC converter based on the multiwinding transformer for renewable energy applications," IEEE Trans. Ind. Appl., Vol. 38, No. 4, pp. 1096-1104, Jul. 2002.

[15] H. Liu, J. Yu, J. Xiong, and H. Shan, "Single-phase inverter voltage control and parallel circulation current suppression," in Proc. 6th Int. Conf. IEEE IPEMC, pp. 1564-1572, 2009.

[16] L. Chen, L. Xiao, W. Hu, and Y. Yan, "Application of coupled inductors in parallel inverter system," in Proc. 6th Int. Conf. ICEMS., Vol. 1, pp.398-401, 2003.

[17] A. F. Witulski, "Modeling and design of transformers and coupled inductors," in Proc. APEC, pp. 589-595, 1993.

[18] B. H. Chowdhury, "Power quality," IEEE Potentials, Vol. 
20, No. 2, pp. 5-11, Apr./May. 2001.

[19] M. M. Morcos and J. C. Gomez, "Electric power quality The strong connection with power electronics," IEEE Power and Energy Mag., Vol. 1, No. 5, pp. 18-25, Sep./Oct. 2003.

[20] Soft Ferrites A User's Guide, Magnetic Materials Producers Association, MMPA SFG-98, pp. 9-14, 30, 1998.

[21] C. W. T. Mclyman, "Transformer design trade offs," in Transformer and Inductor Design Handbook, 3th ed., Marcel Dekker Inc, pp. 5-6, 2004.

[22] L. Chen, L. Xiao, W. Hu, and Y. Yan, "Application of coupled inductors in parallel inverter system," in Proc. 6th Int. Conf. ICEMS, pp. 398-401, 2003.

[23] J. M. Choe, S. G. Ra, B. J. Byen, and G. H. Choe, "Parallel PCS interconnection current surge elimination technique using coupled inductor," in Proc. 15th Int. Conf. IEEE ICIT, pp. 524-528, 2014.

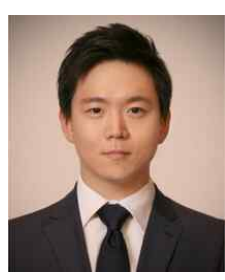

Jung-Muk Choe was born in Seoul, Korea. $\mathrm{He}$ received his B.S., M.S., and Ph.D. in Electrical Engineering from Konkuk University, Seoul, Korea in 2006, 2008, and 2014, respectively. He was a researcher for LSIS, Korea from 2008 to 2009 . He is currently a postdoctoral researcher at Virginia Tech, Blacksburg, VA, USA. His research interests include modeling and control power converters.

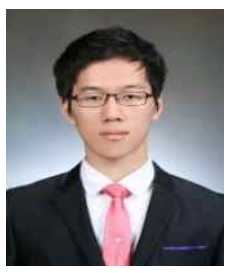

Byeng-Joo Byen was born in Seoul, Korea. He received his B.S. and M.S. in 2011 and 2013, respectively. He is currently pursuing his Ph.D. in Power Electronics at Konkuk University, Seoul, Korea. His research interests include electric vehicle chargers and DC distribution technology related to intelligent grids.

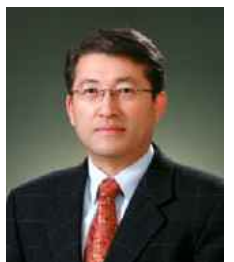

Gyu-Ha Choe was born in Pusan, Korea. He received his B.S., M.S., and Ph.D. from Seoul National University, Seoul, Korea in 1978, 1980, and 1986, respectively. Since 1980, he has been with the Department of Electrical Engineering, Konkuk University, Seoul, Korea where he is currently a professor and the director of the Energy Electronics Research Center. Dr. Choe was the President (2007-2008) of the Korean Institute of Power Electronics. His research interests are in the fields of harmonic cancellation and active power filtering, PWM control for AC voltage regulators and inverter welding machines, PCS design of Brown's gas generation, photovoltaic and fuel-cell generation, various technologies related to DC distribution, and electric vehicle charging with smart grids. 